\title{
Impacts of cloud microphysics on trade wind cumulus: which cloud microphysics processes contribute to the diversity in a large eddy simulation?
}

\author{
Yousuke Sato*, Seiya Nishizawa, Hisashi Yashiro, Yoshiaki Miyamoto, Yoshiyuki Kajikawa and Hirofumi Tomita
}

\begin{abstract}
This study investigated the impact of several cloud microphysical schemes on the trade wind cumulus in the large eddy simulation model. To highlight the differences due to the cloud microphysical component, we developed a fully compressible large eddy simulation model, which excluded the implicit scheme and approximations as much as possible. The three microphysical schemes, the one-moment bulk, two-moment bulk, and spectral bin schemes were used for sensitivity experiments in which the other components were fixed. Our new large eddy simulation model using a spectral bin scheme successfully reproduced trade wind cumuli, and reliable model performance was confirmed. Results of the sensitivity experiments indicated that precipitation simulated by the one-moment bulk scheme started earlier, and its total amount was larger than that of the other models. By contrast, precipitation simulated by the two-moment scheme started late, and its total amount was small. These results support those of a previous study. The analyses revealed that the expression of two processes, (1) the generation of cloud particles and (2) the conversion from small droplets to raindrops, were crucial to the results. The fast conversion from cloud to rain and the large amount of newly generated cloud particles at the cloud base led to evaporative cooling and subsequent stabilization in the sub-cloud layer. The latent heat released at higher layers by the condensation of cloud particles resulted in the development of the boundary layer top height.
\end{abstract}

Keywords: Large eddy simulation; Shallow clouds

\section{Background}

The effect of clouds is one of the most uncertain factors in climate projection and numerical weather prediction. Shallow clouds (e.g., stratus, stratocumulus, shallow cumulus) play particularly important roles in the energy budget of the earth through radiation process because they cover a broad area of the earth (e.g., Randall et al. 1984). The 5th Intergovernmental Panel on Climate Change (IPCC) report suggested that the uncertainties with regards to shallow clouds should be reduced for reliable assessments (IPCC AR5, Stocker et al. 2013).

In global scale models (e.g., general circulation model $(\mathrm{GCM})$ ) and regional models with coarse grid spacing, shallow clouds are usually expressed by parameterizations

\footnotetext{
* Correspondence: yousuke.sato@riken.jp

RIKEN Advanced Institute for Computational Science, 7-1-26 Minatojima-Minami-machi, Chuo-ku, Kobe, Hyogo 650-0047, Japan
}

(e.g., Tiedtke 1993; Considine et al. 1997; Kain 2004), but these parameterizations have not been able to effectively simulate the shallow cloud cover observed from satellites (e.g., Chepfer et al. 2008; Naud et al. 2010).

To improve the expression of shallow cloud, the results of large eddy simulation (LES) models have been utilized. For example, Bretherton and Park (2009) used the results of an LES model to develop a new moist turbulent parameterization. Suzuki et al. (2004) and Posselt and Lohmann (2008) introduced an autoconversion parameterization that was typically used in an LES model (Khairoutdinov and Kogan 2000) into a global scale model. Many studies using LES models have been conducted to determine the characteristics of shallow cloud and improve large-scale modeling (e.g., Wang and Feingold 2009; Xue et al. 2008, Savic-Jovcic and Stevens 2008, Yamaguchi and Randall 2012). However, the 
results of LES models are diverse, as indicated by several LES model intercomparison studies targeting shallow cloud (e.g., Stevens et al. 2005; Ackerman et al. 2009; van Zanten et al. 2011; Siebesma et al. 2003). It has been suggested that the difference in the microphysical schemes used in LES models is one of the reasons for the diversity in the results (Ackerman et al. 2009; van Zanten et al. 2011). However, it is difficult to investigate the exact effect of the different cloud microphysical schemes (i.e., the effect on the results that comes from changing the cloud microphysical scheme while keeping all other components fixed), because each LES model uses a different scheme, not only in cloud microphysics but also many other components (e.g., governing equation, turbulent scheme, advection scheme, and others). Thus, it is also difficult to determine which microphysical processes contribute most to the diversity of the LES results. Sensitivity experiments, which change only the cloud microphysical scheme, are required to better understand the exact effects of the cloud microphysical scheme.

The kinematic driver (KiD) model developed by Shipway and Hill (2012) enables us to conduct sensitivity simulations by changing only the cloud microphysics. Using $\mathrm{KiD}$, we can consider the exact effects of the differences in cloud microphysical schemes. However, KiD ignores feedbacks to the atmosphere, even though the feedbacks of microphysics can affect the microphysical properties of shallow clouds and the turbulent structure of the boundary layer (e.g., Stevens et al. 1998; Wang et al. 2010). It is necessary to consider the feedback of microphysical processes on the dynamics when determining which process causes the diversity in the results of LES models. We should use the model that excludes approximation and implicit schemes as much as possible, because these features also affect the cloud microphysical properties simulated by the model.

This study developed a model that satisfies these requirements. Using the model, we attempted to reproduce the diversity in the results of the LES model used in van Zanten et al. (2011) and to determine impact of the various cloud microphysical schemes. Three types of cloud microphysical schemes (one-moment bulk, twomoment bulk, and spectral bin schemes) were considered in this study, because these three schemes have been used in previous intercomparison studies.

Of the several types of shallow cloud, we focused on trade wind cumulus because their variability in the results of LES models was larger than that of other types of shallow clouds. For example, the variability of surface precipitation in an intercomparison of trade wind cumulus (van Zanten et al. 2011) was larger than that in an intercomparison of stratocumulus (Ackerman et al. 2009). van Zanten et al. (2011) proposed that one of the reasons for the diversity in the microphysical properties of trade wind cumuli was the different cloud microphysical models. They interpreted that a simple (one-moment bulk) microphysical scheme produced large amounts of precipitation (i.e., Table 3 of van Zanten et al. (2011)) and liquid water simulated by one-moment bulk schemes tended to be distributed in the lower layer. By contrast, the liquid water was located in the higher layer, and the precipitation flux was small in most of the two-moment schemes (i.e., Figure 6a of van Zanten et al. (2011)). In this study, we confirmed the validity of their interpretation through a simulation using our new fully compressible LES model and determined the main processes contributing to the diversity in the results of LES model intercomparison studies.

\section{Methods}

\section{Experimental setup, dynamic framework, turbulence model, and external forcing}

This section describes the common parts of the model with its experimental setup (i.e., the dynamic framework, turbulence model, and external forcing). The different parts of the microphysical schemes are highlighted in the subsequent section.

The dynamic model used in this study is an LES model that is included in the Scalable Computing for Advanced Library and Environment library (SCALE). Henceforth, we call this LES model SCALE-LES. The details of SCALE-LES are found at http://scale.aics.riken.jp/.

A fully compressible system is adopted for the governing equation of SCALE-LES. The prognostic variables are the three-dimensional momentum $(\rho u, \rho v, \rho w)$, total density $(\rho)$, mass-weighted potential temperature $(\rho \theta)$, and mass concentration of tracers $\left(\rho q_{\mathrm{s}}\right)$, where $q_{\mathrm{s}}$ includes specific humidity, ratio of mass, and number concentration ratio of hydrometeors to total mass. Explicit time integration is used in all directions. Furthermore, the fourth-order central difference scheme is adopted for spatial discretization to avoid the numerically implicit diffusion that would be induced by odd-ordered difference schemes. The three-step Runge-Kutta scheme is adopted. To retain stability of the model, fourth-order superviscosity/diffusion is applied for all prognostic variables. Using SCALE-LES, developed as described above, we exclude the effects of approximation in the governing equation system and implicit diffusion as far as possible, enabling a consideration of the effects of the target component (i.e., cloud microphysics in this study).

To guarantee monotonicity, the flux-corrected transport (FCT) scheme (Zalesak 1979) is applied for all prognostic variables except for density. The effects of sub-grid scale turbulence are calculated using a Smagorinsky-type scheme based on Brown et al. (1994) and Scotti et al. (1993). 
The experimental setup is almost the same as that of the previous Global Energy and Water Exchange project (GEWEX) Cloud System Study (GCSS) intercomparison of Rain in Cumulus over the Ocean (RICO) (van Zanten et al. 2011). The calculation domain covers $12.8 \times 12.8 \mathrm{~km}^{2}$ horizontally with a double periodic boundary condition and $4.0 \mathrm{~km}$ vertically. The horizontal and vertical grid intervals are 100 and $40 \mathrm{~m}$, respectively. Rayleigh damping is applied for three-dimensional momentum over the upper atmosphere of $z>3.5 \mathrm{~km}$. The strength of the numerical diffusion is set as $1.25 \times$ $10^{5} \mathrm{~m}^{4} \mathrm{~s}^{-1}$, which is determined by the sensitivity experiment (the results of the sensitivity experiment are shown in Appendix 1 of this paper). The simulations are conducted for $24 \mathrm{~h}$ with time steps $(\Delta t)$ of $0.05,0.15$, and $0.5 \mathrm{~s}$ for dynamics, cloud microphysics, and other physics. The $\Delta t$ for cloud microphysics is determined as the largest time step to avoid artificial noise, and the ratio of $\Delta t$ for dynamics to $\Delta t$ for other physics is set to 10 based on the sensitivity experiments (see Appendix 2 of this paper for details of the sensitivity experiment).

The external forcing of the radiation, the surface flux, and the large-scale horizontal advection are applied in the same way as in van Zanten et al. (2011). The forcing of the large-scale subsidence is applied for all prognostic variables including density, except for $u$ and $v$. In nature, large-scale subsidence generates a divergence of total density, which makes the air mass flow out from the domain. However, it cannot flow out in the compressible model using the configuration of van Zanten et al. (2011) due to the periodicity in the lateral boundary condition. Although this problem can be ignored in the anelastic and Boussinesq systems due to the fixed density, it is necessary to consider this problem in the compressible system. Although no description is available for this problem in van Zanten et al. (2011), the density of each layer should be reduced according to the divergence. The density reduction rate and the equation system with large-scale forcing are given below.

Large-scale subsidence $\left(w_{\mathrm{LS}}\right)$ was given by van Zanten et al. (2011) as:

$$
w_{\mathrm{LS}}=\left\{\begin{array}{cc}
-\frac{0.005}{2260} z & (z<2260 \mathrm{~m}) \\
-0.005 & (z \geq 2260 \mathrm{~m})
\end{array}\right.
$$

where $z$ is the height. Instead of this formulation, we give the subsidence formulated directly to vertical momentum as:

$$
\rho w_{\mathrm{LS}}=\left\{\begin{array}{cl}
-\frac{0.005}{2260} z & (z<2260 \mathrm{~m}) \\
-0.005 & (z \geq 2260 \mathrm{~m})
\end{array}\right.
$$

Consequently, the density reduction rate $(D)$ is given as:

$$
D \equiv \frac{\partial\left(\rho w_{\mathrm{LS}}\right)}{\partial z}=\left\{\begin{array}{c}
-\frac{0.005}{2260} \quad(z<2260 \mathrm{~m}) \\
0 \quad(z \geq 2260 \mathrm{~m})
\end{array}\right.
$$

The continuous equation modified with the subsidence term is given by

$$
\frac{\partial \rho}{\partial t}+\frac{\partial(\rho u)}{\partial x}+\frac{\partial(\rho v)}{\partial y}+\frac{\partial\left(\rho\left(w+w_{\mathrm{LS}}\right)\right)}{\partial z}=D
$$

The density reduction derived from the divergence by the large-scale subsidence is added in the right-hand side (rhs) of Eq. (1). Note that this equation is identical to the equation without large-scale subsidence. The Lagrangian conservation equation of the scalar quantities $(\phi)$ is given as:

$$
\rho \frac{\partial \phi}{\partial t}+\rho u \frac{\partial \phi}{\partial x}+\rho v \frac{\partial \phi}{\partial y}+\rho\left(w+w_{\mathrm{LS}}\right) \frac{\partial \phi}{\partial z}=0
$$

The prognostic variable of SCALE-LES is a massweighted value, and the equation of mass-weighted values is derived from Eqs. (1) and (2) as:

$$
\frac{\partial(\rho \phi)}{\partial t}+\frac{\partial(\rho u \phi)}{\partial x}+\frac{\partial(\rho \nu \phi)}{\partial y}+\frac{\partial\left(\rho\left(w+w_{\mathrm{LS}}\right) \phi\right)}{\partial z}=D \phi
$$

As shown in the rhs of Eq. (3), the scalar quantities $(\phi)$ flow out from each layer of the system by subsidence. The equation for the vertical momentum is modified, as is that of the scalar quantities. The vertical flux $\rho w_{\mathrm{LS}} \phi$ at the top boundary can be determined so that such additional convergence of the flux is canceled with $D \phi$ at the top layer.

\section{Three microphysical schemes}

To reproduce the diversity in the results of the RICO study, three types of cloud microphysical scheme are used for this study: the one-moment bulk microphysical scheme (Tomita 2008), the two-moment bulk scheme (Seiki and Nakajima 2014), and the spectral bin microphysical scheme (Suzuki et al. 2010). The one-moment bulk scheme and the two-moment bulk scheme are based on Berry (1968) and Seifert and Beheng (2001), respectively. Both of the original bulk schemes were used in the RICO study.

The essential difference among the three schemes is their treatment of the size distribution of the number of hydrometeor particles. The one-moment bulk scheme expresses this value by the Marshall-Palmer distribution, with the assumption of a constant total number of particles. By this assumption, only the mass concentration is needed to determine the size distribution. Although the two-moment bulk scheme conceptually treats the size distribution almost the same way, it differs 
from the one-moment bulk scheme in the assumption about the type of size distribution function and in the process of its determination. The two-moment bulk scheme assumes the generalized gamma distribution as the size distribution function, and the size distribution itself is determined not only by the mass concentration but also by the number concentration. In this sense, the two-moment bulk scheme is more sophisticated than the one-moment bulk scheme. The spectral bin scheme is an intrinsically sophisticated method compared with the others. It explicitly predicts the size distribution. To compensate for the detailed expression of size distribution, the spectral bin scheme requires about four- to fivefold larger number of prognostic variables compared with the other two schemes.

Although the three microphysical schemes treat both warm and ice phase cloud, the ice phase was not calculated because the temperature at the model top is greater than $273.15 \mathrm{~K}$. In this case, the categorization of hydrometeors for each scheme is as follows. The one-moment and two-moment bulk schemes address two types of hydrometeors: cloud droplet and raindrop for warm rain process. The spectral bin scheme addresses only a type of water drop, which covers the particle size of both cloud droplets and raindrops. For the spectral bin scheme, the radius of newly generated cloud particles by nucleation is set to $3 \mu \mathrm{m}$ (Suzuki et al. 2006). The size distribution of hydrometeors is discretized to 33 bins; its configuration has been established by several previous studies (e.g., Khain and Sednev 1996; Iguchi et al. 2008). The center of mass of $i$ th bin $\left(m_{i}\right)$ is set by using the $i-1$-th bin $\left(m_{i-1}\right)$ as $m_{i}=1.874$ $m_{i-1}, m_{1}$ is the mass of cloud particles whose radius is $3 \mu \mathrm{m}$.

All three schemes consider the generation of cloud droplets, condensation, evaporation, and sedimentation of cloud hydrometeors. Although the two-moment bulk scheme also considers the breakup of cloud droplets, this difference is minor based on sensitivity experiments examining the breakup process (figure not shown). Sedimentation is calculated by the first-order upwind scheme for all three schemes.

Since the generation of new cloud droplets is one of the critical processes in this experiment, the difference in this process among the schemes should be noted. The mass of newly generated cloud droplets is calculated by saturation adjustment in the one-moment bulk scheme, which was also used in some one-moment bulk schemes in the RICO study. By contrast, it is calculated by the nucleation schemes in the two-moment bulk and spectral bin schemes. The number concentration of the cloud droplets $\left(N_{\mathrm{c}, \text { nucl }}\right)$ generated by the nucleation process is calculated as follows (e.g., Pruppacher and Klett 1997):

$$
N_{\mathrm{c}, \text { nucl }}=N_{0} S_{\mathrm{w}}{ }^{k}
$$

where $S_{\mathrm{w}}$ is supersaturation over water. The constants $N_{0}$ and $k$ are set as $N_{0}=100 \times 10^{6} \mathrm{~m}^{-3}$ and $k=0.462$. This scheme was also used in several models used in the RICO study. The growth of cloud droplets into raindrops is another key issue for this experiment, as well as the underlying creation process. In the bulk scheme, this is expressed as autoconversion and accretion. To investigate the strength of the impact of the autoconversion and accretion processes, we conducted the same simulation with autoconversion and accretion ratios that were twice as large (0.067-fold smaller) as the two-moment (one-moment) scheme. The autoconversion rate $\left(P_{\text {auto }}\right)$ in the one-moment bulk scheme is calculated as in Tomita (2008), which was based on Berry (1968):

$$
\begin{aligned}
& P_{\text {auto }}=\frac{1}{\rho}\left[16.7 \times\left(\rho q_{\mathrm{c}}\right)^{2}\left(5+\frac{3.6 \times 10^{-5} N_{\mathrm{c}, \mathrm{T} 08}}{D_{\mathrm{d}} \rho q_{\mathrm{c}}}\right)\right] \\
& {\left[\mathrm{kg} \mathrm{kg}^{-1} \mathrm{~s}^{-1}\right] \text {, }}
\end{aligned}
$$

where $D_{\mathrm{d}}=0.1456-5.964 \times 10^{-2} \log \left(N_{c, T 08} / 2000\right), q_{\mathrm{c}}$ is the cloud water mixing ratio, and $N_{\mathrm{c}, \text { T08 }}$ is the number concentration of cloud droplets. In Tomita (2008), $N_{\text {c,T08 }}$ was set as $50 \mathrm{~cm}^{-3}$, but in this study, $N_{\text {c,T08 }}$ was set as $70 \mathrm{~cm}^{-3}$ based on the experimental setup in the RICO study (van Zanten et al. 2011). Another autoconversion scheme from Khairoutdinov and Kogan (2000) was implemented into the one-moment bulk scheme because it had performed better than the scheme of Berry (1968) in a GCM (Suzuki et al. 2004). The scheme was also adopted in some models used in the RICO study. $P_{\text {auto }}$ in the Khairoutdinov and Kogan (2000) scheme is calculated as:

$$
P_{\text {auto }}=1350 \times q_{\mathrm{c}}^{2.47} \times N_{\mathrm{c}, \mathrm{T} 08}^{-1.79} \quad\left[\mathrm{kgkg}^{-1} \mathrm{~s}^{-1}\right]
$$

Using the schemes shown above, we attempted to reproduce the diversity of the LES results in the RICO study.

\section{Results and discussion}

\section{Basic performance of SCALE-LES}

The validity of SCALE-LES was confirmed through comparison with a previous study (van Zanten et al. 2011). The results of the spectral bin scheme were regarded as a reference solution of SCALE-LES, because it is the most sophisticated scheme of the three. First, the results of the reference solution were compared with the previous study. As shown in Figs. 1 and 2, the results of our model (SCALE-LES) are within the range between the maximum and minimum of the intercomparison study in terms of temporal evolution and vertical profile 

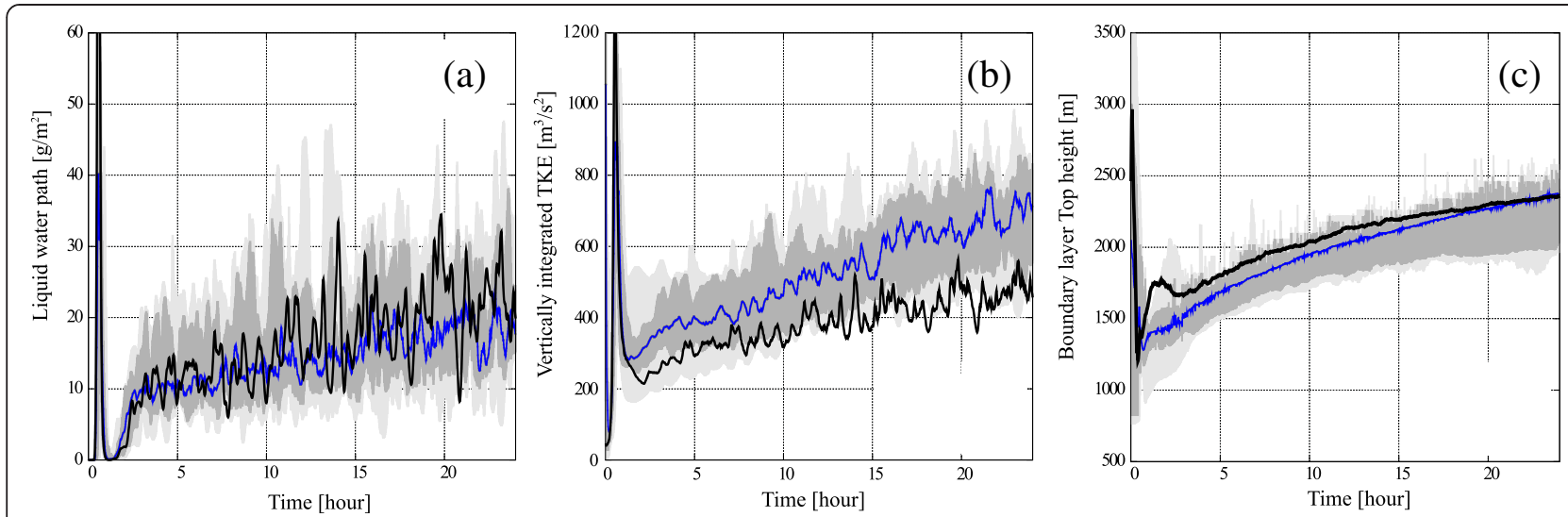

Fig. 1 Comparison of the time evolution between SCALE-LES and a previous intercomparison study. Time evolution of the a liquid water path, b vertically integrated turbulence kinetic energy, and c boundary layer top height averaged over the entire calculation domain simulated by (black line) SCALE-LES, with the spectral bin scheme. The blue line, dark gray shading, and light gray shading indicate the median, range between the first and third quartiles, and range between the maximum and minimum values, respectively, of the previous intercomparison study (van Zanten et al. 2011)

for several quantities. This indicates that our model could reproduce the shallow cumulus simulated by the LES models used in the previous study.

As well as the physical performance, the computational performance and the scalability of SCALE were investigated. The elapsed time for a time step $(\Delta t)$ and the performance efficiency are shown in Table 1. The elapsed time and performance of SCALE-LES do not change when it is used with a large number of Message Passing Interface (MPI) processes (e.g., over 10,000 MPI processes). This indicates that SCALE-LES has excellent scalability and a reasonable performance in massive parallel computing.

\section{Impacts of cloud microphysical scheme on simulation results}

Second, we show the results of the same simulation (RICO) by using three microphysical schemes for investigating the impacts of the cloud microphysical scheme. Figure 3 indicates the differences among the three schemes. The precipitation flux simulated by the twomoment bulk scheme is small, and its peak value is distributed in the upper layer. By contrast, the precipitation flux by the one-moment bulk scheme is large and the peak value locates in the lower layer. The precipitation by the spectral bin scheme is between the other two (Fig. 3a). The trend is consistent with the previous study (Figure 6a of van Zanten et al. 2011).

The impacts of the different cloud microphysical schemes on the vertical distribution of the precipitation flux, the liquid water mixing ratio $\left(q_{1}\right)$, and cloud fraction are clearly shown in Fig. 3a-c. The $q_{1}$ in the onemoment bulk scheme is distributed in the lower layer (the peak value is represented at $z \sim 900 \mathrm{~m}$ ). Table 2 shows the surface precipitation averaged during the last
$4 \mathrm{~h}$ for the three schemes. The precipitation amount in the one-moment bulk scheme is the largest, and the precipitation begins earliest among the three. The surface precipitation over $0.1 \mathrm{~W} \mathrm{~m}^{-2}$ starts at $1.8 \mathrm{~h}$ in the onemoment bulk scheme, at $10.05 \mathrm{~h}$ in the two-moment bulk scheme, and at $2.63 \mathrm{~h}$ in the spectral bin scheme. The liquid water simulated in the two-moment bulk scheme is located in the upper layer (the peak value is located at $z \sim 2400 \mathrm{~m}$ ), and only trace amounts of precipitation reach the surface (Table 2). The cloud fraction of the one-moment scheme is located in the lower layer and is small in the upper layer. On the other hand, the positive cloud fraction in the two-moment bulk scheme reaches a higher layer. The spectral bin scheme simulates an intermediate value between the other two, with the same trend as the RICO study. These results are consistent with the result of the previous study (van Zanten et al. 2011).

The large amount of precipitation in the onemoment bulk scheme carries a large amount of liquid water to the lower layer. As shown in Fig. 3d, the total water mixing ratio $\left(q_{\mathrm{t}}\right)$ of the lower layer (i.e., $z<$ $1500 \mathrm{~m}$ ) in the one-moment bulk scheme is larger than that in the others. Despite the difference in the vertical distribution of liquid water, the liquid water path (LWP) shows the same value (Fig. 3e). By contrast, the cloud coverage of the one-moment scheme is smaller than in the other scheme (Fig. 3f). This implies that the amount of cloud that extends horizontally at the top of boundary layer is small in the one-moment scheme, which is because of the liquid water removed from the cloud layer earlier by precipitation. This is also found in Fig. 3c, where the peak of the cloud fraction does not appear around the top of the boundary layer (i.e., $z \sim 2000 \mathrm{~m}$ ). 

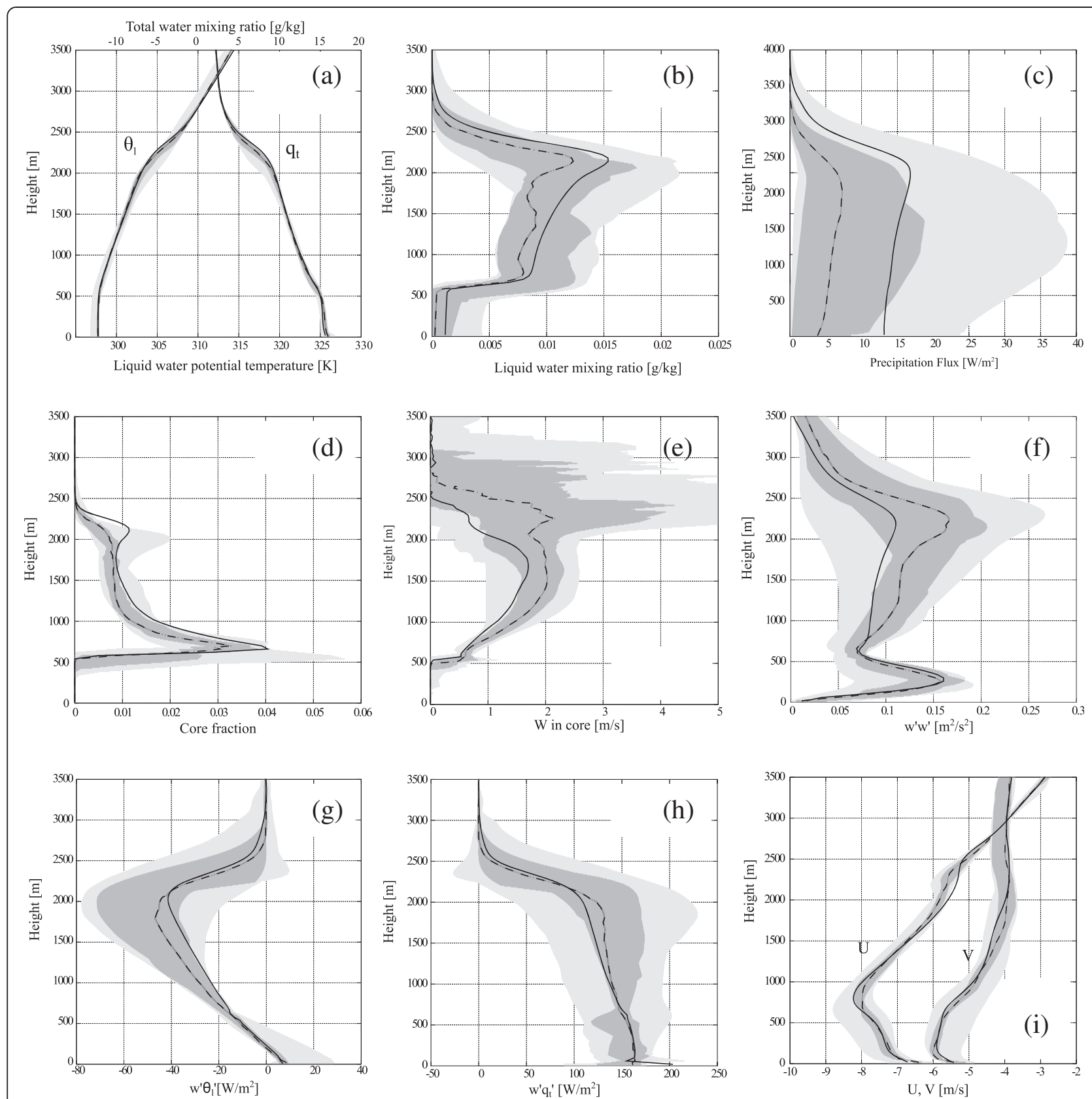

Fig. 2 Comparison of vertical profiles between SCALE-LES and a previous intercomparison study. Horizontally averaged profile of the a liquid water potential temperature $\left(\theta_{1}\right)$ and total water mixing ratio $\left(q_{t}\right)$, b liquid water mixing ratio $\left(q_{1}\right), \mathbf{c}$ precipitation flux, $\mathbf{d}$ cloud fraction, e vertical velocity in cloud core, $\mathbf{f}$ variance of resolved $w^{\prime}, \mathbf{g} w^{\prime} \theta_{1}^{\prime}, \mathbf{h} w^{\prime} q_{t}^{\prime}$, and $\mathbf{i}$ horizontal wind velocity, averaged during the last $4 \mathrm{~h}$. The solid line indicates the results of SCALE-LES. The dashed line, heavy gray shading, and light gray shading indicate the median, range between the first and third quartiles, and range between the maximum and minimum values, respectively, of the previous intercomparison study (van Zanten et al. 2011)

The impacts of cloud microphysics appear not only on the precipitation and vertical distribution of liquid water, but also the turbulent properties such as the turbulence kinetic energy (TKE), the variance in resolved vertical velocity $\left(w^{\prime}\right)$, and boundary layer top height. The boundary layer top height in the two-moment bulk scheme is the highest among the three schemes, whereas the onemoment bulk scheme simulates the lowest boundary layer height. This trend in boundary layer height continues to the end of the simulation time, as shown in Fig. 4a, and the difference among the schemes gradually becomes large. The variance in $w^{\prime}$ (Fig. 4c) and TKE (Fig. 4d) in the two-moment bulk scheme attributes a larger value to the upper layer. By contrast, those in the one-moment scheme are smaller in the upper layer. Vertically integrated TKE tends to be large and small in the 
Table 1 Computational performance of SCALE-LES

\begin{tabular}{|c|c|c|c|c|c|c|}
\hline Number of core & 16 & 2048 & 8192 & 32,768 & 131,072 & $663,552^{a}$ \\
\hline $\begin{array}{l}\text { (Number of MPI } \\
\text { process) }\end{array}$ & (2) & (256) & (1024) & $(4096)$ & $(16,384)$ & $(82,944)$ \\
\hline Elapsed time $\left(\mathrm{s}\right.$ step $\left.^{-1}\right)$ & 2.528 & 2.172 & 2.443 & 2.017 & 1.995 & 2.113 \\
\hline $\begin{array}{l}\text { Performance } \\
\text { efficiency (\%) }\end{array}$ & 5.5 & 6.3 & 5.6 & 6.8 & 6.9 & 6.5 \\
\hline
\end{tabular}

Elapsed time (s step $\left.{ }^{-1}\right)$ and performance efficiency (\%) of SCALE-LES measured using the two-moment bulk microphysical scheme. The performance was measured through an experiment in which the number of grids for each MPI process was the same (weak scaling test) on the $\mathrm{K}$ computer

${ }^{\text {a }}$ This test used all nodes of the $\mathrm{K}$ computer

two-moment and the one-moment bulk schemes, respectively (Fig. 4b).

From the results shown above, we concluded that the turbulent properties of the boundary layer as well as the cloud microphysical properties of cumulus are significantly affected by the different microphysical schemes when other components are unchanged. These results support the proposal of van Zanten et al. (2011) that the use of different cloud microphysical schemes is one of the main reasons for the diversity among LES models. We have confidence in this conclusion because direct effects other than the cloud microphysical schemes were excluded in our experiments.

\section{Reasons for the differences among the results of the three schemes}

The impacts of the cloud microphysical schemes are clearly indicated by the differences in the boundary layer top height, vertical distribution of liquid water, and the precipitation flux, as shown in the previous section. The reasons for these differences will be discussed in this section.

Since the impacts of each cloud microphysical scheme originate from the expression of the liquid water in each scheme, an examination of the tendency of $q_{1}$ and potential temperature $(\theta)$ in the cloud microphysical process

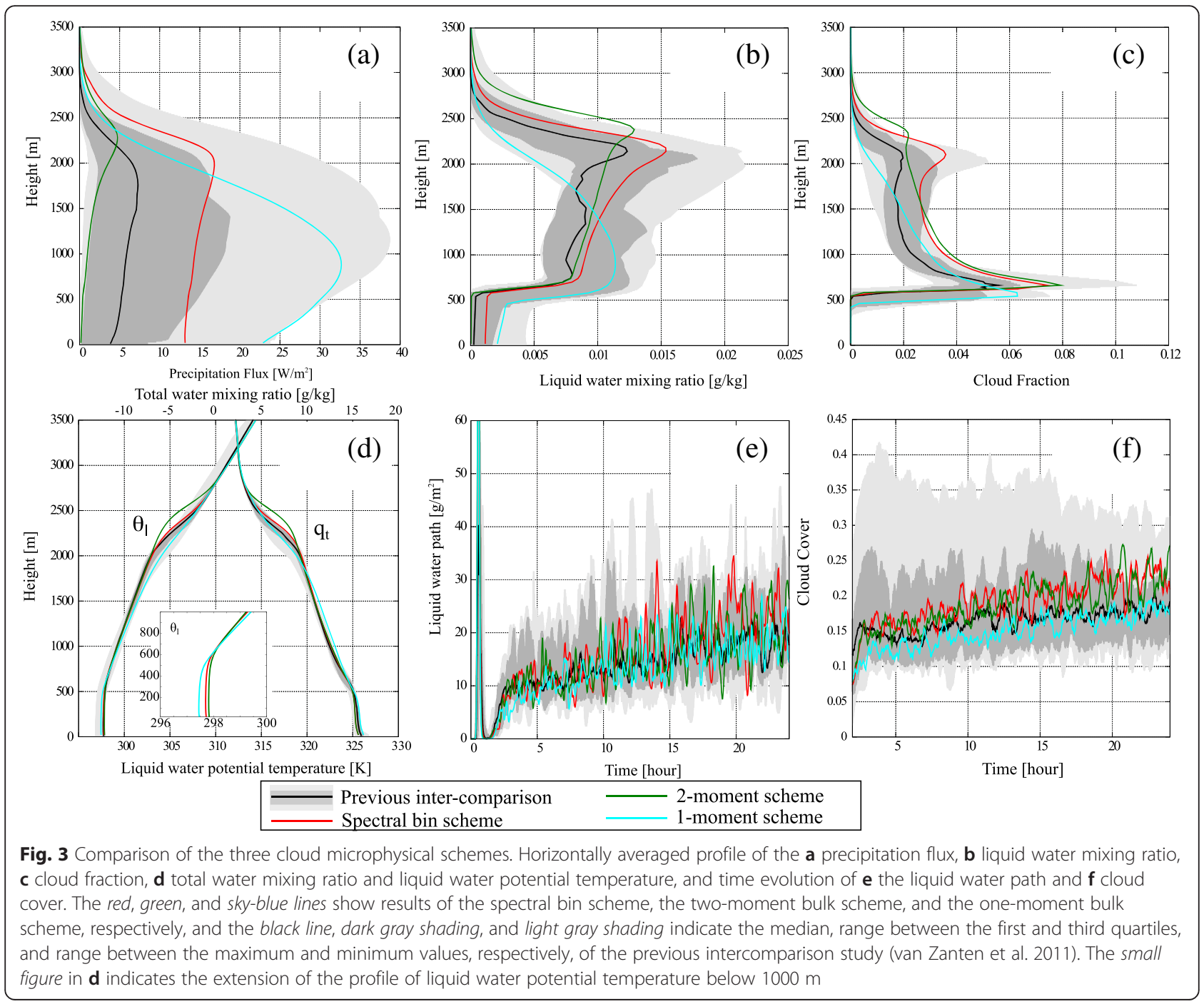


Table 2 Comparison of surface precipitation flux. The surface precipitation flux averaged over the whole calculation domain during the last $4 \mathrm{~h}$ of calculation

\begin{tabular}{llll}
\hline Scheme & One-moment bulk & Two-moment bulk & Spectral bin \\
\hline $\begin{array}{l}\text { Precipitation flux } \\
\left(\mathrm{W} \mathrm{m}^{-2}\right)\end{array}$ & 22.89 & 0.174 & 13.17 \\
\hline
\end{tabular}

is helpful for understanding the differences among the results. We first investigate the difference during $t=3-4 \mathrm{~h}$ of the calculation, because the effects of feedbacks of cloud physics to dynamics is not large and it is easy to interpret the difference. The tendencies at each height averaged during $t=3 \mathrm{~h}$ to $t=4 \mathrm{~h}$ are shown in Fig. 5a, b. The results from $t=0 \mathrm{~h}$ to $t=3 \mathrm{~h}$ were removed to ignore the effects of spin-up. The effect of sedimentation was omitted from the tendencies. The generation of liquid water at the cloud base in the one-moment bulk scheme is more active than that in the others (Fig. 5a). This is attributed to the difference in the mechanism for generating cloud particles. In the one-moment bulk scheme, newly generated cloud particles are calculated by saturation adjustment, whereas in the other schemes, they are calculated based on Eq. (4). Because the saturation adjustment does not permit supersaturation, it can generate larger amounts of liquid water at the cloud base than that can be generated by the scheme based on Eq. (4), which allows for supersaturation. This large amount of liquid water generation results in a large heat release at the cloud base (Fig. 5b) and subsequently a strong vertical velocity (Fig. 5c).

In addition to the large amount of liquid water generated in the one-moment bulk scheme, it is clear from the particle size distribution that the conversion from cloud to rain is fast. Size distributions at the lower part of cloud (i.e., $z=1000 \mathrm{~m}$ ) are shown in Fig. 5d. The generation of drizzle and raindrops (i.e., particles over $40 \mu \mathrm{m}$ in radius) in the lower part of the cloud is active in the one-moment bulk scheme, whereas small cloud
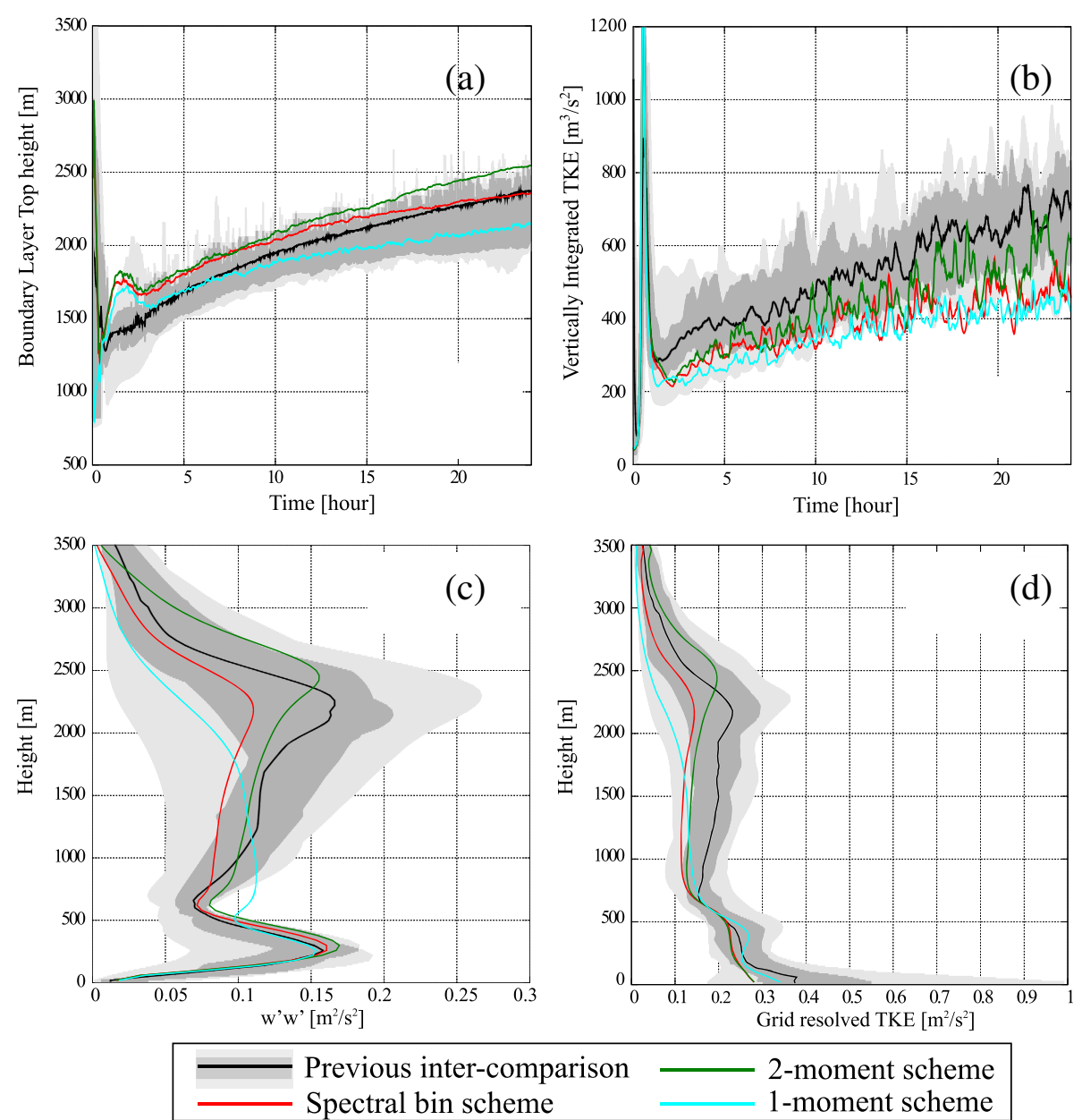

Fig. 4 Comparison of turbulence properties between the three schemes. Time evolution of the a boundary layer top height and $\mathbf{b}$ vertically integrated turbulence kinetic energy (grid resolved + sub-grid scale) and horizontally averaged profile of $\mathbf{c}$ the variance of resolved $w^{\prime}$ and $\mathbf{d}$ grid-resolved turbulence kinetic energy averaged during the last $4 \mathrm{~h}$ of calculation 

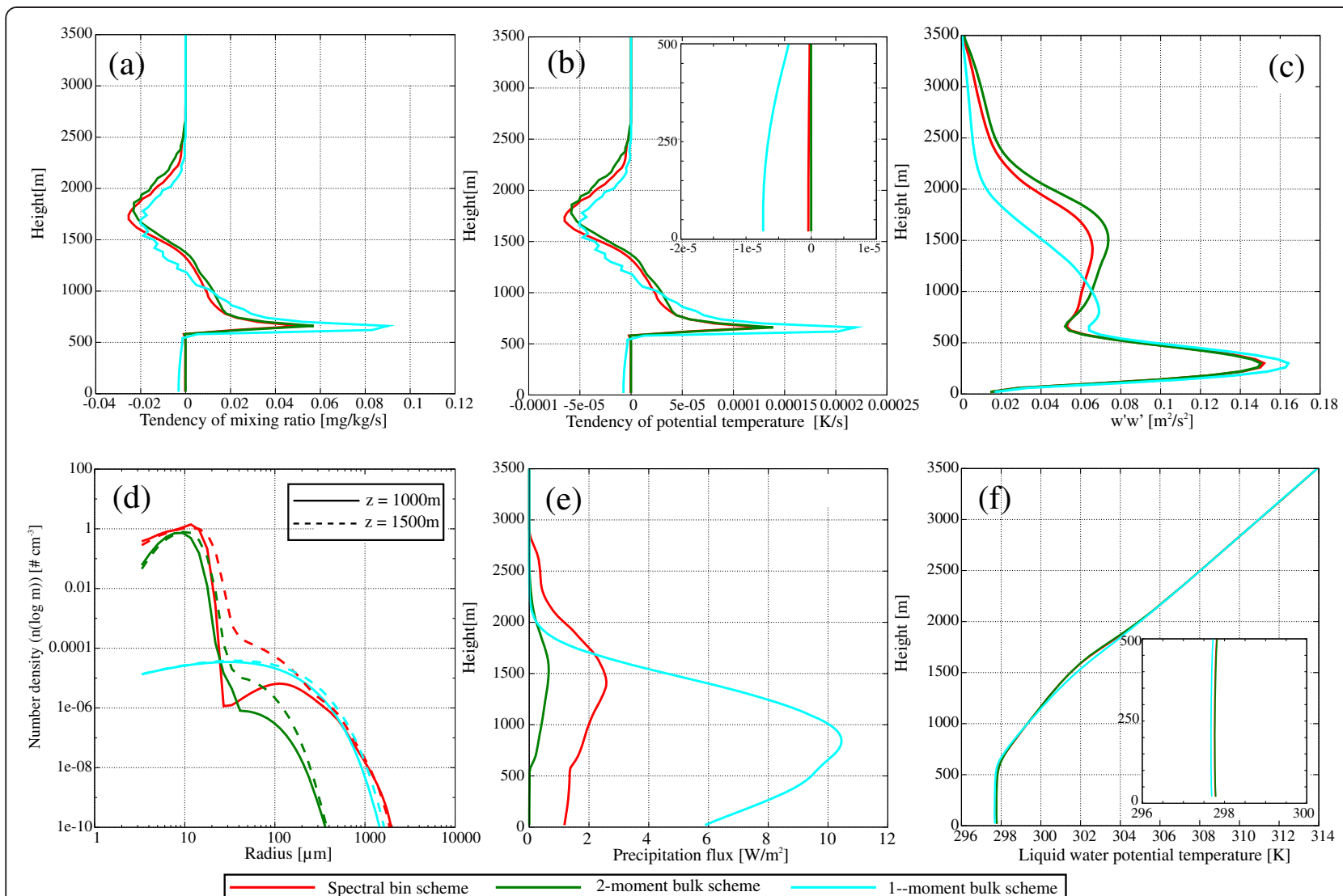

Fig. 5 Profiles and size distribution function averaged during $t=3 \sim 4 \mathrm{~h}$. Horizontally averaged profile of the a tendency of the liquid water, $\mathbf{b}$ tendency of potential temperature, $\mathbf{c}$ variance of $\boldsymbol{w}^{\prime}$, e precipitation flux, and $\mathbf{f}$ liquid water potential temperature averaged during $t=3$ to 4 h. $\mathbf{d}$ Number density distribution $(n(\log \mathrm{m})$ ) averaged over the whole cloudy grid at (solid) $z=1000 \mathrm{~m}$ and (dashed) $z=1500 \mathrm{~m}$, where $n$ and $m$ are the number concentration and mass of liquid water, respectively. The red, green, and sky-blue lines show results of the spectral bin, two-moment bulk, and one-moment bulk schemes, respectively. The extended figures in $\mathbf{b}$ and $\mathbf{f}$ show the tendencies of potential temperature and liquid water potential temperature below $500 \mathrm{~m}$, respectively

particles are dominant in the two-moment bulk schemes. This indicates that the conversion from cloud to rain in the one-moment bulk scheme is faster than that in the others, and larger numbers of raindrops are generated in the lower part of the cloud by the one-moment bulk scheme.

The generation of large raindrops leads to the fast terminal velocity of the hydrometeors and a large precipitation flux in the one-moment bulk scheme (Fig. 5e), which, in turn, leads to the large precipitation flux at the surface and the fast onset of surface precipitation. Figure $5 \mathrm{a}, \mathrm{b}$ also show that the peak negative tendency of $q_{1}$ and $\theta$ near the cloud top $(z \sim 1700 \mathrm{~m})$, which corresponds to the evaporation of cloud droplets at the top of the boundary layer, is located in a lower layer in the one-moment scheme than in the others. This indicates that the large precipitation volume and large cloud size in the one-moment bulk scheme restrain the cloud particles from reaching the upper layer. Therefore, the boundary layer top height of the one-moment bulk scheme becomes lower (Fig. 4a).

The large amount of raindrops in the one-moment scheme creates feedback for the thermodynamic structure below the cloud. The water loading due to raindrops leads to active evaporative cooling below the cloud (shown in the negative tendency of $q_{1}$ and $\theta$ below the cloud as shown in Fig. 5a, b and the lower potential temperature below the cloud shown in Fig. 5f). This evaporative cooling stabilizes the boundary layer and suppresses the heat transfer from the ground to the upper part of the boundary layer, which is shown in the fact that the positive tendency of $\theta$ in the one-moment bulk scheme does not reach $z>1200 \mathrm{~m}$ but reaches $z \sim$ $1400 \mathrm{~m}$ in the other scheme. This supports Stevens et al. (1998), who indicated that precipitation suppresses cloud growth and entrainment. This suppression can limit the development of the boundary layer and results in a more stable boundary layer. 
The difference between the two-moment bulk and the spectral bin schemes in the tendency of $q_{1}$ and $\theta$ are relatively small. However, the difference in size distribution function between the two schemes is clearly apparent (Fig. 5d). A larger amount of raindrops $(r>100 \mu \mathrm{m})$ were present in the spectral bin scheme than in the case in the two-moment bulk scheme. It is indicated that the conversion from cloud droplets to raindrops is slow in the two-moment bulk scheme. Because the amount of large raindrops is small in the two-moment bulk scheme (shown as green lines in Fig. 5d), liquid water is carried to the upper layer more easily than in the other schemes. The liquid water evaporates at the top of the boundary layer. This is shown by the negative tendency of $q_{\mathrm{l}}$, and by $\theta$ locating in a higher layer in the two-moment bulk scheme than in the others (Fig. 5a, b).

The presence of larger particles in the spectral bin scheme subsequently increases the rate of collisions with other particles, which leads to more rapid growth of particles and earlier precipitation in the spectral bin scheme than in the two-moment bulk scheme. This provides feedback due to the large amount of precipitation, which is the same feedback that occurs in the one-moment bulk scheme.

With the feedback, the differences among the three schemes increase with the integration time. The difference in the boundary layer top height in the three schemes becomes large as the integration time increases (Fig. 4a), and the difference in the liquid water potential temperature below clouds during the last $4 \mathrm{~h}$ (Fig. $3 \mathrm{~d}$ ) is larger than at $t=3-4 \mathrm{~h}$ (Fig. 5f). The differences in the tendencies of $\theta$ and $q_{1}$ shown above also become clear (figure not shown).

In summary, the one-moment bulk scheme creates a larger amount of precipitation, because the saturation adjustment was adopted in the one-moment bulk scheme, and raindrops are subsequently produced by the fast conversion from cloud to raindrops. This results in earlier onset and larger amounts of surface precipitation. The evaporative cooling by raindrops, which occurs actively below the cloud, stabilized the boundary layer in the onemoment bulk scheme.

The two-moment scheme creates raindrops more slowly, resulting in a smaller amount of precipitation compared with the other schemes. The smaller amount of precipitation results in an active latent heat release in the higher layer (shown in Fig. 5b) and a high boundary layer. The spectral bin scheme shows an intermediate rate of conversion and creates an intermediate amount of precipitation, with values between those of the two-moment and onemoment bulk schemes.

The large number of cloud particles newly generated at the cloud bottom by saturation adjustment, the difference in the speed of conversion from cloud to rain, and the difference in the timing of the surface precipitation all originate from the variety of microphysical schemes used in this study. The differences in each scheme would not always appear when the results of other one-moment, twomoment, and spectral bin schemes are compared. By contrast, the evaporative cooling and subsequent stabilization of the sub-cloud layer and the suppression of the development of boundary layer height, which appeared in the results of the one-moment scheme used in this study, can be expected if the fast conversion from cloud to rain or the active generation of cloud particles at the cloud base occurs as a result of natural phenomena, regardless of which scheme is used. The active latent heat release and high boundary layer, which appeared in the two-moment scheme used in this study, can also be expected. The results are commonly expected for trade wind cumulus.

\section{Speed of conversion from cloud to rain}

The analyses in the previous sections hint that the performance of the bulk microphysical schemes could be modified by changing the nucleation schemes and the conversion speed from cloud to rain. In the bulk scheme, autoconversion and accretion are the main processes involved in the conversion from cloud to rain. To obtain information for the modification of the parameterization of these two processes, a comparison of the autoconversion and accretion rates among the three schemes is helpful. Figure 6 shows the autoconversion and accretion rates

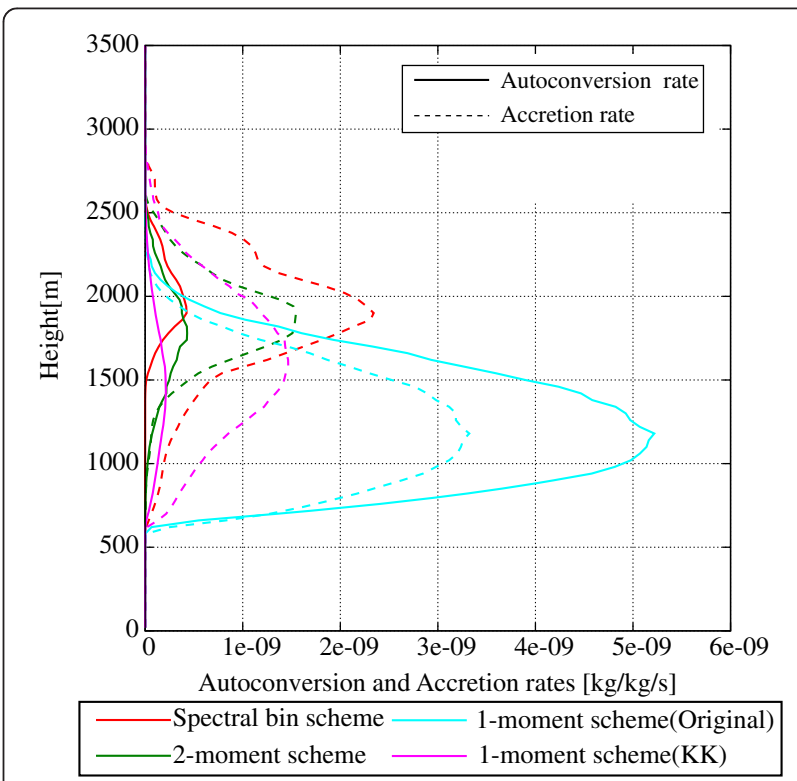

Fig. 6 Autoconversion and accretion rate averaged during $t=3 \sim 4 \mathrm{~h}$. The horizontally averaged (solid line) autoconversion rate and (dashed line) accretion rate simulated by the spectral bin scheme (red), two-moment scheme (green), one-moment scheme (sky blue), and one-moment scheme with the Khairoutdinov and Kogan (2000) scheme (pink), averaged during $t=3 \sim 4 \mathrm{~h}$ 
averaged during $t=3 \sim 4 \mathrm{~h}$. The autoconversion rate of the spectral bin scheme is regarded as the rate of increasing mass of raindrops (defined as liquid particles whose radius is larger than $40 \mu \mathrm{m}$ ) generated by the coagulation between cloud particles (defined as liquid particles whose radius is smaller than $40 \mu \mathrm{m}$ ). The accretion rate of the spectral bin scheme is determined as the increasing rate of mass due to the coagulation between cloud particles and raindrops. Figure 6 shows that the autoconversion rate of the one-moment scheme is about 15 times larger than that of the spectral bin scheme. By contrast, the accretion rate of the two-moment scheme is $1.5 \sim 2$ times smaller than that of the spectral bin scheme. Based on these results, the sensitivity of these two processes in each scheme was investigated and is discussed in the next section.

\section{Sensitivity of the autoconversion to the one-moment bulk scheme}

As shown above, the one-moment bulk scheme overestimates the conversion speed from cloud droplet to raindrop. We first investigated the difference between the original autoconversion scheme of Tomita (2008) and that of Khairoutdinov and Kogan (2000) shown in Eq. (6). The results of the one-moment bulk scheme with the Khairoutdinov and Kogan (2000) scheme are more similar to the results of the spectral bin scheme and the previous study than those calculated by Eq. (5) (Fig. 7). This indicates that the conversion speed calculated by Eq. (5) is too fast for shallow clouds because the validity of the onemoment bulk scheme with Eq. (5) was confirmed through experiments with deep convective clouds (Tomita 2008).

In addition to the experiment with the Khairoutdinov and Kogan (2000) scheme, other sensitivity experiments
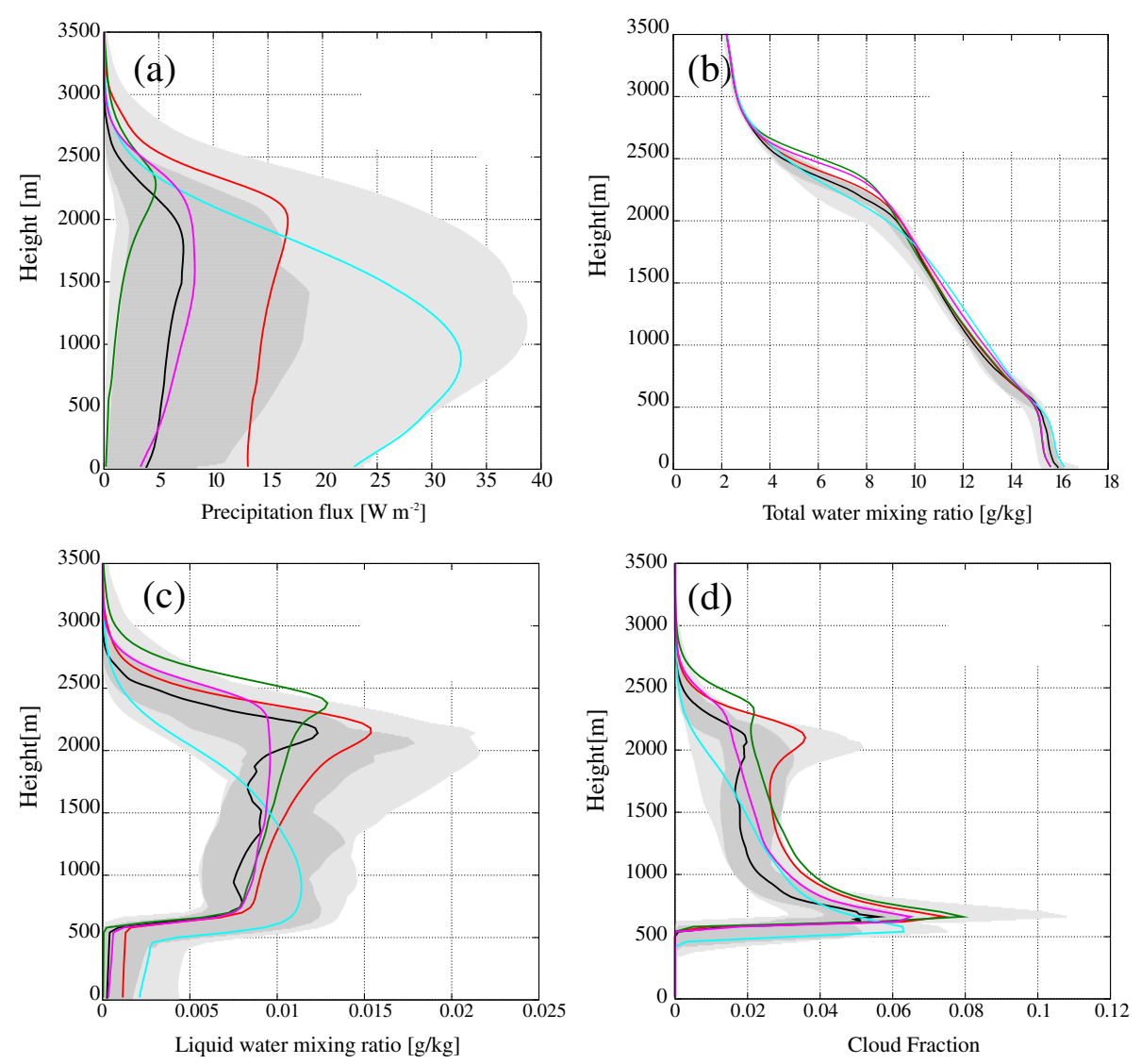

$\begin{array}{ll}\text { Previous inter-comparison } & \text { 2-moment scheme } \longrightarrow \\ \text { Spectral bin scheme } & \text { 1-moment scheme(Original) }\end{array}$

Fig. 7 Cloud microphysical properties simulated by Khairoutdinov and Kogan's auto conversion scheme. Horizontally averaged profile of the a precipitation flux, b total water mixing ratio $\left(q_{\mathrm{t}}\right)$, c liquid water mixing ratio, and $\mathbf{d}$ cloud fraction averaged during the last $4 \mathrm{~h}$. The red, green, sky-blue, and pink lines show results by the spectral bin scheme, the two-moment bulk scheme, the one-moment bulk scheme, and one-moment bulk scheme using the Khairoutdinov and Kogan (2000) autoconversion rate, respectively. The black line, dark gray shading, and light gray shading indicate the median, range between the first and third quartiles, and range between the maximum and minimum values, respectively, of the previous intercomparison study (van Zanten et al. 2011) 
were conducted by reducing the autoconversion rate. Based on the analyses in Fig. 6, a 0.067-fold (i.e., 1/15) smaller autoconversion rate than the default value was used for the sensitivity experiment. Another sensitivity experiment with an accretion rate that was 0.067 -fold smaller than the default value was also conducted. Figure 8 shows the profile of $q_{1}$ and the precipitation flux, which were calculated using the smaller autoconversion and accretion rate. It can be seen that a small autoconversion rate results in liquid water locating in the upper layer, whereas it does not locate in the upper layer when the accretion rate was reduced to the same extent as the autoconversion rate. Hence, the autoconversion process is more sensitive to the production of raindrops.

Sensitivity of the accretion to the two-moment bulk scheme Contrasting the one-moment bulk scheme, the twomoment bulk scheme underestimates the conversion speed from cloud to raindrop. We speculate that the faster conversion from cloud droplet to raindrop in the two-moment scheme produced similar results using the spectral bin scheme. Sensitivity experiments were conducted by changing both the autoconversion and accretion rates of the two-moment scheme. Based on the analyses in Fig. 6, a twofold increase in the accretion rate was used, and a twofold increase of the autoconversion rate was also used for the sensitivity experiment. Figure 9 shows the results of these experiments. In the twomoment bulk scheme, both the precipitation rate and $q_{1}$ increase when the autoconversion rate is doubled. However, doubling the autoconversion rate does not result in a peak value of $q_{1}$ and a precipitation flux in the lower layer as simulated by the one-moment bulk scheme. By contrast, the precipitation flux simulated when the accretion rate is doubled is considerably larger than both the default and when the autoconversion rate is doubled. This indicates that the accretion process was the major contributor to the creation of liquid water in the lower layer in the two-moment bulk scheme.

In short, the sensitivity of the accretion and the autoconversion processes to the cloud microphysical properties differ between the schemes.

\section{Component level intercomparison}

In this study, we investigated the exact effects of the various cloud microphysical schemes on model simulations of trade wind cumulus. If we change components other than the cloud microphysical scheme (e.g., dynamical core, turbulence scheme, advection scheme), the response of the cloud microphysical properties would change as suggested by van Zanten et al. (2011). It is necessary to conduct sensitivity experiments by changing each component while keeping all other components fixed, as we did when targeting the cloud microphysical scheme in this study. We refer to these sensitivity experiments as a "Component level intercomparison".

Grabowski (2014) suggested a piggyback approach to better understand the exact effects of cloud microphysics and the interaction between microphysics and dynamics. This approach can be also applied to the other components. Using a component level intercomparison and the piggyback approach, we can discuss the effects

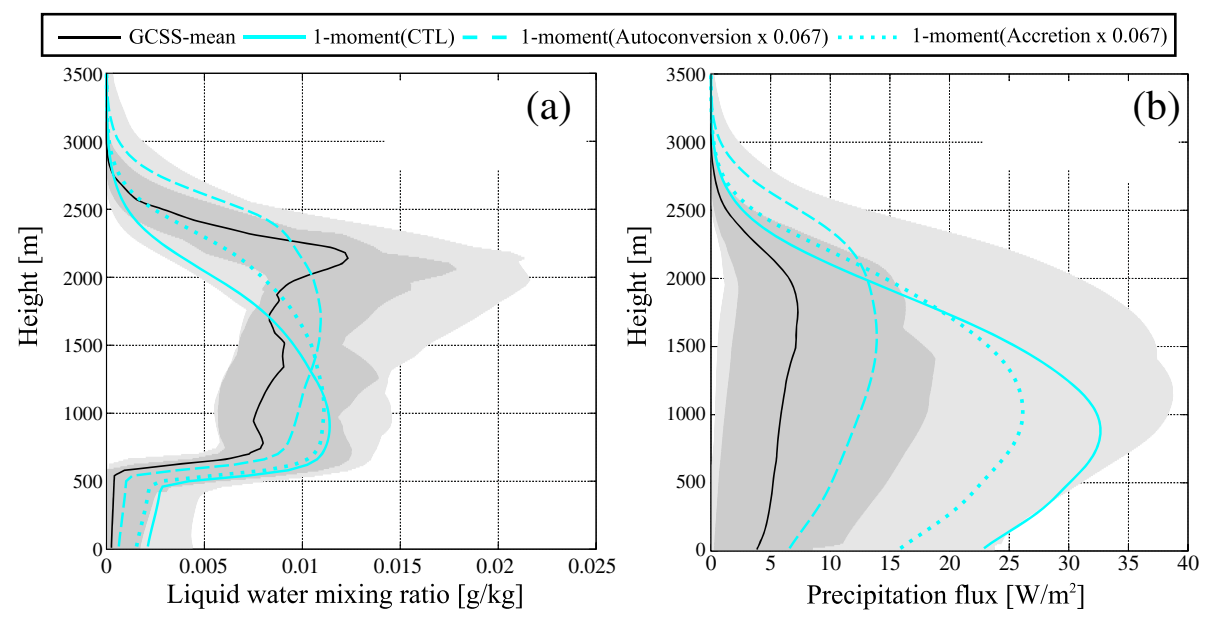

Fig. 8 Cloud microphysical properties simulated in the sensitivity experiment with a varying conversion ratio in the one-moment scheme. Horizontally averaged profile of the a liquid water mixing ratio $\left(q_{1}\right)$ and $\mathbf{b}$ precipitation flux averaged during the last $4 \mathrm{~h}$. The solid sky-blue, dashed sky-blue, and dotted sky-blue lines show the results using the one-moment bulk scheme with the default autoconversion rate, one-moment bulk scheme with an autoconversion rate 0.067 -fold (i.e., 1/15) smaller, and one-moment bulk scheme with accretion ratio 0.067 -fold smaller, respectively. The black line, dark gray shading, and light gray shading indicate the median, range between the first and third quartiles, and range between the maximum and minimum values, respectively, for a previous intercomparison study (van Zanten et al. 2011) 


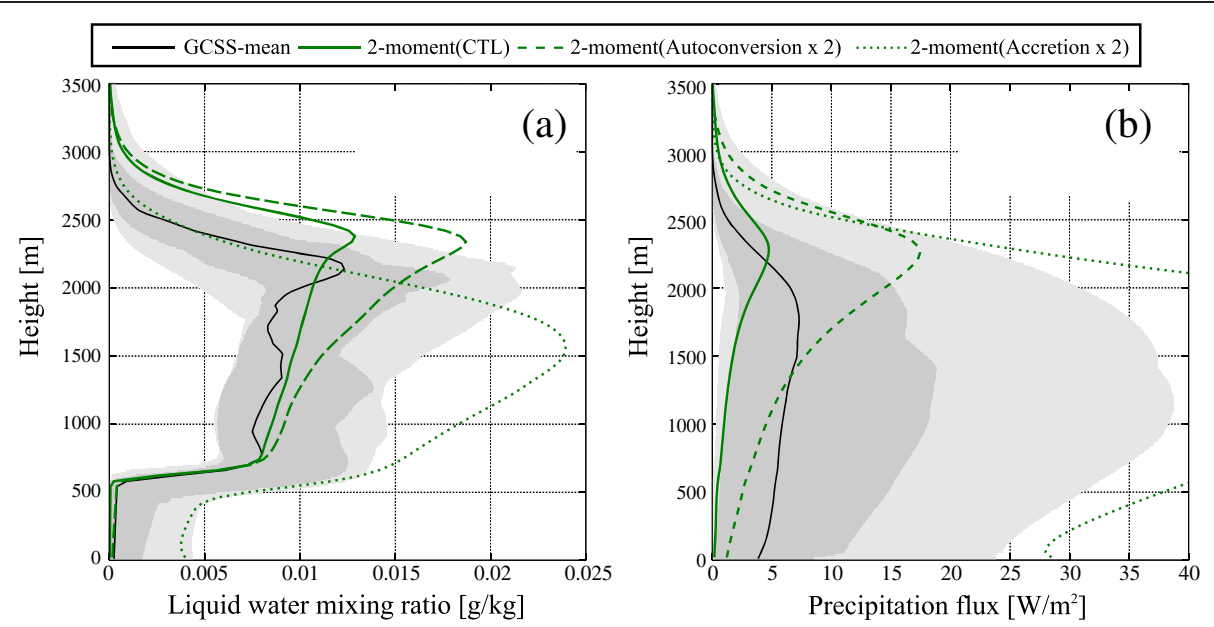

Fig. 9 Cloud microphysical properties simulated in the sensitivity experiment with a changing conversion ratio in the two-moment scheme. The horizontally averaged profile of the $\mathbf{a}$ liquid water mixing ratio $\left(q_{1}\right)$ and $\mathbf{b}$ precipitation flux averaged during the last $4 \mathrm{~h}$. The solid green, dashed green, and dotted green lines show the results using the two-moment bulk scheme with the default autoconversion rate, two-moment bulk scheme with an autoconversion rate twice as large as the default, and two-moment bulk scheme with an accretion ratio twice as large as the default. The black line, dark gray shading, and light gray shading indicate the median, range between the first and third quartiles, and the range between the maximum and minimum values, respectively, for a previous intercomparison study (van Zanten et al. 2011)

of each component separately and obtain knowledge that would improve the parameterization of global scale models or regional models with coarse resolution.

\section{Conclusions}

In this study, we developed a large eddy simulation model (SCALE-LES), which excludes approximations and implicit schemes as much as possible. The results of a benchmark test indicated that SCALE-LES effectively reproduces the trade wind cumuli simulated in a previous LES intercomparison study (van Zanten et al. 2011). Using SCALE-LES, we investigated the impacts of cloud microphysical schemes on shallow cumulus and investigated which processes were critical for the diversity observed in previous LES intercomparison studies. Three types of cloud microphysical scheme, the one-moment bulk scheme of Tomita (2008), the two-moment bulk scheme of Seiki and Nakajima (2014), and the one-moment spectral bin scheme of Suzuki et al. (2010), were implemented with SCALE-LES for the sensitivity experiments.

The results indicated that the precipitation at the surface increases, in order, from the two-moment bulk scheme to the spectral bin scheme and the one-moment bulk scheme. Surface precipitation begins first in the
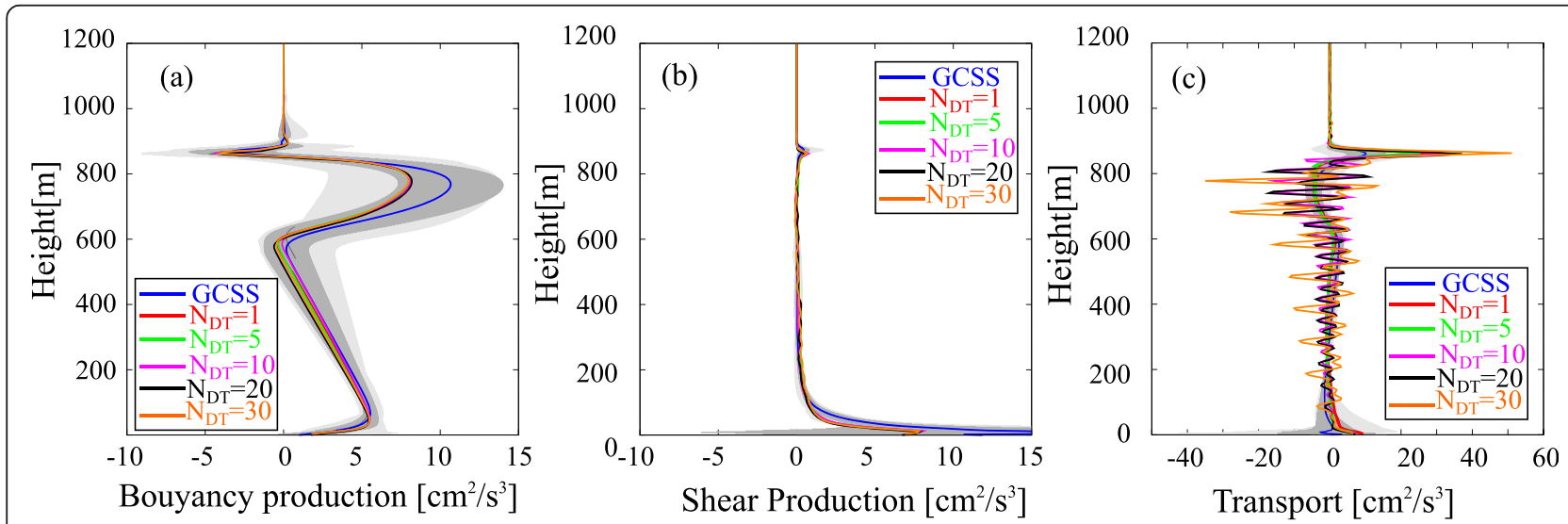

Fig. 10 Cloud microphysical properties in the sensitivity experiment of $N_{D T}\left(=\Delta t_{\text {microphy }} / \Delta t_{\text {dyn }}\right)$. Hourly averaged profile of the a buoyancy production, $\mathbf{b}$ shear production, and $\mathbf{c}$ transport terms averaged over the entire calculation domain during the last hour of each simulation. The red, green, pink, black, and orange lines represent the results of $N_{D T}=1,5,10,20$, and 30, respectively. The blue line, dark gray shading, and light gray shading indicate the mean, standard deviation, and the range between the maximum and minimum values, respectively, from a previous intercomparison study (Stevens et al. 2005) 
Table 3 List of non-dimensional coefficient for sensitivity experiment

\begin{tabular}{llll}
\hline Non-dimensional coefficient $(\gamma)$ & $\gamma=10^{-3}$ & $\gamma=10^{-5}$ & $\gamma=10^{-7}$ \\
\hline The strength of the numerical filter & $1.25 \times 10^{5}$ & $1.25 \times 10^{3}$ & $1.25 \times 10^{1}$ \\
\hline The value of the numerical filter $\left(\mathrm{m}^{4} \mathrm{~s}^{-1}\right)$ for each experiment &
\end{tabular}

The value of the numerical filter $\left(\mathrm{m}^{4} \mathrm{~s}^{-1}\right)$ for each experiment

one-moment bulk scheme, followed in order by the spectral bin and two-moment bulk schemes. These results support the suggestion of a previous intercomparison study (van Zanten et al. 2011)

Our analyses confirmed that the differences between the schemes were derived mainly from the generation of cloud particles and the speed of conversion from cloud droplets to raindrops. The differences in the two processes originated from the differences in the microphysical schemes used. By contrast, the phenomena generated by this variety, i.e., evaporative cooling and stabilization below the cloud and a low boundary layer, active latent heat release, and a high boundary layer can be expected regardless of the scheme used, if the active conversion from cloud to rain and the active generation of new cloud particles occur in nature.

The sensitivity of the autoconversion and accretion processes to the cloud microphysical properties simulated by the bulk microphysical schemes was also investigated. In the two-moment bulk scheme the accretion process was more sensitive to the cloud microphysical properties, whereas the autoconversion was more sensitive in the one-moment bulk scheme. These results indicate that the tuning method of the microphysical scheme differs from scheme to scheme, and a component level intercomparison is useful to obtain the exact method for each scheme.

\section{Appendix 1}

Sensitivity of the ratio of the physical time step to the dynamical time step. In this study, the time step of dynamics $\left(\Delta t_{\text {dyn }}\right)$, cloud microphysics $\left(\Delta t_{\text {microphy }}\right)$, and other physics $\left(\Delta t_{\text {phy }}\right)$ were set as $0.05,0.15$, and $0.5 \mathrm{~s}$, respectively. The time step of dynamics was determined by the Courant-Friedrichs-Lewy (CFL) condition for the acoustic wave. The time step for physics (except for cloud microphysics) was set as $10 \times \Delta t_{\text {dyn }}$ based on the sensitivity experiment (Nishizawa et al., 2015). The $\Delta t_{\text {microphy }}$ was determined in sensitivity experiments examining the ratio of $\Delta t_{\text {microphy }}$ to $\Delta t_{\mathrm{dyn}}$. The results of the sensitivity experiments examining the ratio $N_{\mathrm{DT}}$ $\left(=\Delta t_{\text {microphy }} / \Delta t_{\text {dyn }}\right)$ are shown in this section. For this sensitivity test, the experimental setup of the second Dynamics and Chemistry of Marine Stratocumulus Research Flight 1 (DYCOMS-II RF01) (Stevens et al. 2005) was used. In this study, the experimental setup of the RICO study was used in most cases, but the effects of the acoustic wave appeared more clearly in the DYCOMS-II case (figure not shown). Consequently, the ratio $\left(N_{\mathrm{DT}}\right)$ was determined using the DYCOMS-II RF01 experimental setup. For this sensitivity experiment, $\Delta t_{\text {dyn }}$ was set as $0.01 \mathrm{~s}$ and $N_{\mathrm{DT}}$ was swept from 1 to 30 (i.e., $\Delta t_{\text {microphy }}$ was set from 0.01 to $0.3 \mathrm{~s}$ ).

The results of the sensitivity experiment indicated that the effects of $N_{\mathrm{DT}}$ were mostly small (figures not shown), except for the TKE budget. Figure 10 shows the profile of the buoyancy production term, shear production term, and transport term of TKE production. The transport term was quite noisy when $N_{\mathrm{DT}}$ was large $\left(N_{\mathrm{DT}}>10\right)$. Noise is also present in the shear production term. This noise was derived from the acoustic wave that was generated at every time step of the microphysical processes. When $N_{\mathrm{DT}}$ was

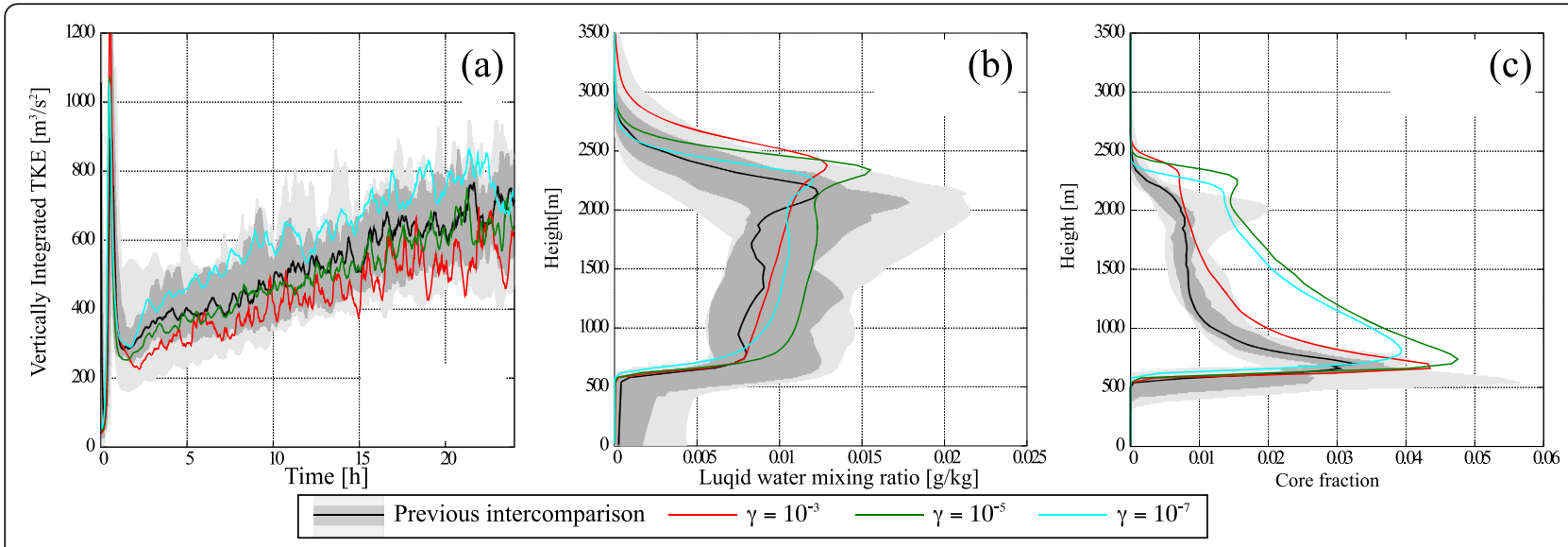

Fig. 11 Results of a sensitivity experiment of the strength of numerical diffusion. Time evolution of the a vertically integrated turbulence kinetic energy averaged over the whole calculation domain and the profile of the $\mathbf{b}$ liquid water mixing ratio and $\mathbf{c}$ cloud fraction averaged over the whole calculation domain during the last $4 \mathrm{~h}$. The red, green, and sky-blue line shows the results with the coefficient $(\gamma)$ as $10^{-3}, 10^{-5}$, and $10^{-7}$, respectively. The black line, thick gray shade, and thin gray shade indicate the median, range between the first and third quartiles, and range between the maximum and minimum values of a previous intercomparison study, respectively (van Zanten et al. 2011) 
large, the variation of $\theta$ at each step of the microphysical processes was also large. The large variation in $\theta$ generates an acoustic wave, which produced the noise. This indicates that $N_{\mathrm{DT}}$ should be smaller than 5 to render the effects of the acoustic wave negligibly. From these results and for safety, $N_{\mathrm{DT}}$ was set as 3 for the RICO experiment (i.e., $\Delta t_{\text {microphy }}=3 \times \Delta t_{\text {dyn }}$ ).

\section{Appendix 2}

Numerical filter. This section describes the sensitivity experiments of the strength of the numerical diffusion. The $n$th ordered superviscosity/diffusion is defined as:

$$
\begin{aligned}
& \frac{\partial}{\partial x}\left[v \rho \frac{\partial^{n-1} f}{\partial x^{n-1}}\right] \quad f \in\left\{u, v, w, \theta, q_{\mathrm{s}}\right\} \\
& \frac{\partial}{\partial x}\left[v \frac{\partial^{n-1} \rho}{\partial x^{n-1}}\right]
\end{aligned}
$$

The $v$ is written as:

$$
v=(-1)^{\frac{n}{2}+1} \gamma \frac{\Delta x^{n}}{2^{n} \Delta t}
$$

where $\gamma$ is a non-dimensional coefficient, $\Delta x$ is the grid spacing, and $n$ is the order of the numerical filter. This study adopted a fourth-order numerical diffusion (i.e., $n=4)$ to dampen the artificial noise. $n$ was set as 4 because of the computational efficiency.

To investigate the sensitivity of the strength of the numerical diffusion, simulations of the RICO study were conducted while changing the strength of the numerical diffusion. Based on the rough estimation of Nishizawa et al. (2015), the non-dimensional coefficient $(\gamma)$ should be smaller than $O\left(10^{-3}\right)-O\left(10^{0}\right)$ for $n=4$. Thus, $\gamma$ was changed from $10^{-3}$ to $10^{-7}$. The strength of the numerical diffusion for each $\gamma$ is shown in Table 3. The two-moment bulk scheme was used for the sensitivity experiment. As a result of the numerical diffusion, one-dimensional sinusoidal two-grid noise will decay to $1 / e$ with a $1 / \gamma$ time step.

Figure 11 shows the results of the sensitivity experiment. The vertically integrated TKE increased with a weakening of the numerical filter, even though the TKE of all experiments was located in the range between the maximum and minimum of the previous studies. This is because a strong numerical diffusion can efficiently dampen small-scale turbulence. As well as the TKE, the liquid water mixing ratio of all the sensitivity experiments was also located in the range of previous intercomparison studies regardless of the strength of the numerical diffusion. However, the cloud fraction simulated with a small numerical diffusion (i.e., $\gamma \leq 10^{-5}$ ) was much larger than that of the intercomparison study, and the cloud fraction was completely outside the range of the inter comparison studies. The cloud fraction, core fraction, and variance of $w$ ' were also outside the range of the inter comparison studies when $\gamma$ was smaller than $10^{-5}$ (figure not shown). The temporal evolution of the cloud fraction indicates that the large cloud fraction, with small numerical diffusion, seems to originate from artificial noise. However, it is difficult to identify the reason for the large cloud fraction being artificial noise. The same experiment must be conducted with a fine grid resolution to divide all of the elements of the wave into a physically meaningful wave and artificial noise. However, computational limitations prevented us from conducting these experiments. Consequently, $\gamma$ was determined using the results of the intercomparison study (van Zanten et al. 2011) as a reference solution, and $\gamma$ was set as $10^{-3}$ (i.e., the strength of the numerical diffusion is $\left.1.25 \times 10^{5} \mathrm{~m}^{4} \mathrm{~s}^{-1}\right)$.

\section{Abbreviations}

DYCOMS: Dynamics and Chemistry of Marine Stratocumulus; GCSS: GEWEX Cloud System Study; GEWEX: Global Energy and Water Exchange project; KiD: the kinematic driver; LES: large eddy simulation; LWP: liquid water path; MPI: Message Passing Interface; RICO: Rain in Cumulus over the Ocean; SCALE: Scalable Computing for Advanced Library and Environment; TKE: turbulence kinetic energy.

\section{Competing interests}

The authors declare that they have no competing interests.

\section{Authors' contributions}

YS implemented the cloud microphysical schemes in the SCALE library, designed this study, conducted the numerical simulations, analyzed the results of the simulations, and developed the manuscript. SN, HY, and YM developed the main frames of the SCALE library. YK collaborated with the corresponding author in the creation of the manuscript. HT proposed the development of the SCALE library. All authors read and approved the final manuscript.

\section{Acknowledgement}

Part of the results is obtained by the K computer at the RIKEN Advanced Institute for Computational Science. This work was supported by FOCUS Establishing Supercomputing Center of Excellence. SCALE-LES developed by Team-SCALE of the RIKEN Advanced Institute for Computational Sciences. The data from GCSS intercomparison studies used in several figures were downloaded from http://www.knmi.nl/samenw/rico/.

Received: 23 February 2015 Accepted: 6 August 2015

Published online: 18 August 2015

\section{References}

Ackerman AS, van Zanten MC, Stevens B, Savic-Jovcic V, Bretherton CS, Chlond A, Golaz J-C, Jiang H, Khairoutdinov M, Krueger SK, Lewellen DC, Lock A, Moeng C-H, Nakamura K, Petters MD, Snider JR, Weinbrecht S, Zulauf M (2009) Largeeddy simulations of a drizzling, stratocumulus-topped marine boundary layer. Mon Weather Rev 137:1083-1110. doi:10.1175/2008MWR2582.1

Berry EX (1968) Modification of the warm rain process. In: Proceeding of First Conference on Weather Modification., pp 81-85

Bretherton CS, Park S (2009) A new moist turbulence parameterization in the Community Atmosphere Model. J Clim 22:3422-3448. doi:10.1175/2008JCLI2556.1 Brown AR, Derbyshire SH, Mason PJ (1994) Large-eddy simulation of stable atmospheric boundary layers with a revised stochastic subgrid model. Q J R Meteorol Soc 120:1485-1512. doi:10.1002/qj.49712052004

Chepfer H, Bony S, Winker D, Chiriaco M, Dufresne JL, Sèze G (2008) Use of CALIPSO lidar observations to evaluate the cloudiness simulated by a climate model. Geophys Res Lett 35:1-6. doi:10.1029/2008GL034207 
Considine G, Curry JA, Wielicki B (1997) Modeling cloud fraction and horizontal variability in marine boundary layer clouds. J Geophys Res 102:13517. doi:10.1029/97JD00261

Grabowski WW (2014) Extracting microphysical impacts in large-eddy simulations of shallow convection. J Atmos Sci 71:4493-4499. doi:10.1175/JAS-D-14-0231.1

Iguchi T, Nakajima T, Khain AP, Saito K, Takemura T, Suzuki K (2008) Modeling the influence of aerosols on cloud microphysical properties in the east Asia region using a mesoscale model coupled with a bin-based cloud microphysics scheme. J Geophys Res 113:D14215. doi:10.1029/2007JD009774

Kain, JS (2004) The Kain-Fritsch convective parameterization: An update. J Appl Meteorol. doi:10.1175/1520-0450(2004)043<0170:TKCPAU>2.0.CO;2

Khain AP, Sednev I (1996) Simulation of precipitation formation in the Eastern Mediterranean coastal zone using a spectral microphysics cloud ensemble model. Atmos Res 43:77-110. doi:10.1016/S0169-8095(96)00005-1

Khairoutdinov M, Kogan Y (2000) A new cloud physics parameterization in a large-eddy simulation model of marine stratocumulus. Mon Weather Rev 128:229-243. doi:10.1175/1520-0493(2000)128<0229:ANCPPI>2.0.CO;2

Naud CM, Del Genio AD, Bauer M, Kovari W (2010) Cloud vertical distribution across warm and cold fronts in cloudsat-CALIPSO data and a general circulation model. J Clim 23:3397-3415. doi:10.1175/2010JCLI3282.1

Nishizawa S, Yashiro H, Sato Y, Miyamoto Y, Tomita H (2015) Influence of grid aspect ratio on planetary boundary layer turbulence in large-eddy simulations. Geosci Model Dev Discuss 8:6021-6094. doi:10.5194/gmdd-8-6021-2015

Posselt R, Lohmann U (2008) Introduction of prognostic rain in ECHAM5: design and single column model simulations. Atmos Chem Phys 8:2949-2963. doi:10.5194/acpd-7-14675-2007

Pruppacher, HR, and Klett, JD, 1997, Microphysics of Clouds and Precipitation, 2nd ed., Kluwer Academic Publisher, Dordrecht, The Netherlands, 954pp.

Randall DA, Coakley JA, Lenschow DH, Fairall CW, Kropfli RA (1984) Outlook for research on subtropical marine stratification clouds. Bull Am Meteorol Soc 65:1290-1301. doi:10.1175/1520-0477(1984)065<1290:OFROSM>2.0.CO;2

Savic-Jovcic V, Stevens B (2008) The structure and mesoscale organization of precipitating stratocumulus. J Atmos Sci 65:1587-1605. doi:10.1175/2007JAS2456.1

Scotti A, Meneveau C, Lilly DK (1993) Generalized Smagorinsky model for anisotropic grids. Phys Fluids A Fluid Dyn 5:2306-2308. doi:10.1063/1.858537

Seifert A, Beheng KD (2001) A double-moment parameterization for simulating autoconversion, accretion and self collection. Atmos Res 59-60:265-281. doi:10.1016/S0169-8095(01)00126-0

Seiki T, Nakajima T (2014) Aerosol effects of the condensation process on a convective cloud simulation. J Atmos Sci 71:833-853. doi:10.1175/JAS-D-12-0195.1

Shipway BJ, Hill AA (2012) Diagnosis of systematic differences between multiple parametrizations of warm rain microphysics using a kinematic framework. Q J R Meteorol Soc 138:2196-2211. doi:10.1002/qj.1913

Siebesma A, Bretherton CS, Brown A, Chlond A, Cuxart J, Duynkerke P, Jiang H, Khairoutdinov M, Lewellen D, Moeng C-H, Sanchez E, Stevens B, Stevens DE (2003) A large-eddy simulation intercomparison study of shallow cumulus convection. J Atmos Sci 60:1201-1219. doi:10.1175/15200469(2003)060<1201:AALESIS>2.0.CO;B2

Stevens B, Cotton WR, Feingold G, Moeng C-H (1998) Large-eddy simulations of strongly precipitating, shallow, stratocumulus-topped boundary layers. J Atmos Sci 55:3616-3638. doi:10.1175/1520-0469(1998)055<3616:LESOSP > 2.0.CO;2

Stevens B, Moeng C-H, Ackerman AS, Bretherton CS, Chlond A, de Roode S, Edwards J, Golaz J-C, Jiang H, Khairoutdinov M, Kirkpatrick MP, Lewellen DC, Lock A, Müller F, Stevens DE, Whelan E, Zhu P (2005) Evaluation of largeeddy simulations via observations of nocturnal marine stratocumulus. Mon Weather Rev 133:1443-1462. doi:10.1175/MWR2930.1

Stocker, TF, Qin D, Plattner G-K, Tignor M, Allen SK, Boschung J, Nauels A, Xia Y, Bex V, and Midgley PM (2013), IPCC, 2013: Climate Change 2013: The Physical Science Basis, Cambridge University Press, Cambridge, United Kingdom and New York, NY, USA.

Suzuki K, Nakajima T, Nakajima TY, Khain A (2006) Correlation pattern between effective radius and optical thickness of water clouds simulated by a spectral bin microphysics cloud model. SOLA 2:116-119. doi:10.2151/sola.2006-030

Suzuki K, Nakajima T, Nakajima TY, Khain AP (2010) A study of microphysical mechanisms for correlation patterns between droplet radius and optical thickness of warm clouds with a spectral bin microphysics cloud model. J Atmos Sci 67:1126-1141. doi:10.1175/2009JAS3283.1

Suzuki K, Nakajima T, Numaguti A, Takemura T, Kawamoto K, Higurashi A (2004) A study of the aerosol effect on a cloud field with simultaneous use of GCM modeling and satellite observation. J Atmos Sci 61:179-194. doi:10.1175/1520-0469(2004)061<0179:ASOTAE >2.0.CO;2

Tiedtke M (1993) Representation of clouds in large-scale models. Mon Weather Rev 121:3040-3061. doi:10.1175/1520-0493(1993)121<3040:ROCILS>2.0.CO;2

Tomita H (2008) New microphysical schemes with five and six categories by diagnostic generation of cloud ice. J Meteorol Soc Japan 86A:121-142. doi:10.2151/jmsj.86A.121

van Zanten MC, Stevens B, Nuijens L, Siebesma AP, Ackerman AS, Burnet F, Cheng A, Couvreux F, Jiang $H$, Khairoutdinov $M$, Kogan $Y$, Lewellen DC, Mechem D, Nakamura K, Noda A, Shipway BJ, Slawinska J, Wang S, Wyszogrodzki A (2011) Controls on precipitation and cloudiness in simulations of trade-wind cumulus as observed during RICO. J Adv Model Earth Syst 3:M06001. doi:10.1029/2011MS000056

Wang H, Feingold G (2009) Modeling mesoscale cellular structures and drizzle in marine stratocumulus. Part II: the microphysics and dynamics of the boundary region between open and closed cells. J Atmos Sci 66:3257-3275. doi:10.1175/2009JAS3120.1

Wang H, Feingold G, Wood R, Kazil J (2010) Modelling microphysical and meteorological controls on precipitation and cloud cellular structures in Southeast Pacific stratocumulus. Atmos Chem Phys 10:6347-6362. doi:10.5194/acp-10-6347-2010

Xue H, Feingold G, Stevens B (2008) Aerosol effects on clouds, precipitation, and the organization of shallow cumulus convection. J Atmos Sci 65:392-406. doi:10.1175/2007JAS2428.1

Yamaguchi T, Randall DA (2012) Cooling of entrained parcels in a large-eddy simulation. J Atmos Sci 69:1118-1136. doi:10.1175/JAS-D-11-080.1

Zalesak ST (1979) Fully multidimensional flux-corrected transport algorithms for fluids. J Comput Phys 31:335-362. doi:10.1016/0021-9991(79)90051-2

\section{Submit your manuscript to a SpringerOpen ${ }^{\circ}$ journal and benefit from:}

- Convenient online submission

- Rigorous peer review

- Immediate publication on acceptance

- Open access: articles freely available online

- High visibility within the field

- Retaining the copyright to your article

Submit your next manuscript at $>$ springeropen.com 